\title{
Prediction of the bottom ash formed in a coal-fired power plant using artificial neural networks
}

\author{
Tugce Bekat ${ }^{\mathrm{a}}$, Muharrem Erdogan ${ }^{\mathrm{a}}$, Fikret Inal ${ }^{\mathrm{a}, *}$, Ayten Genc ${ }^{\mathrm{b}}$ \\ ${ }^{a}$ Department of Chemical Engineering, Izmir Institute of Technology, Gulbahce, Urla, 35430 Izmir, Turkey \\ ${ }^{\mathrm{b}}$ Department of Environmental Engineering, Zonguldak Karaelmas University, 67100 Zonguldak, Turkey
}

\section{A R T I C L E I N F O}

\section{Article history:}

Received 17 February 2012

Received in revised form

25 April 2012

Accepted 28 June 2012

Available online 21 July 2012

\section{Keywords:}

Artificial neural networks

Bottom ash

Pulverized coal-fired power plant

\begin{abstract}
A B S T R A C T
The amount of bottom ash formed in a pulverized coal-fired power plant was predicted by artificial neural network modeling using one-year operating data of the plant and the properties of the coals processed. The model output was defined as the ratio of amount of bottom ash produced to amount of coal burned (Bottom ash/Coal burned). The input parameters were the moisture contents, ash contents and lower heating values of the coals. The total 653 data were divided into two groups for the training ( $90 \%$ of the data) and the testing (10\% of the data) of the network. A three-layer, feed-forward type network architecture with back-propagation learning was used in the modeling study. The activation function was sigmoid function. The best prediction performance was obtained for a one hidden layer network with 29 neurons. The learning rate and the tolerance value were 0.2 and 0.05 , respectively. $R^{2}$ (coefficient of determination) values between the actual (Bottom ash/Coal burned) ratios and the model predictions were 0.988 for the training set and 0.984 for the testing set. In addition, the sensitivity analysis indicated that the ash content of coals was the most effective parameter for the prediction of the ratio of bottom ash to coal burned.
\end{abstract}

(C) 2012 Elsevier Ltd. All rights reserved.

\section{Introduction}

For performance prediction and control of combustion processes, generally computer modeling is applied using analytical codes or numerical methods. These methods require laborious and time-consuming solution procedures of multi-parameter complex differential equations. Furthermore, in some cases, these methods may not be applicable due to lack of information about the physical and chemical steps. In this context, artificial neural networks (ANNs) have the potential to be better, quicker, and more practical alternative to these traditional methods, for modeling and predicting the behavior of combustion processes [1].

In the recent years, ANN modeling technique has been used to predict various toxic emissions and other environmental issues related to combustion processes [2,3], as well as combustion of coal. Chong et al. [4] modeled the gaseous emissions emanating from the combustion of lump coal on a chain-grate stoker-fired boiler using ANNs; and obtained encouraging results for prediction of pollutant emissions, as an alternative to the mathematical modeling of the physical process. Hao et al. [5] used ANN approach combined with

\footnotetext{
* Corresponding author. Tel.: +90 232750 6654; fax: +90 2327506645 .

E-mail address: fikretinal@iyte.edu.tr (F. Inal).
}

genetic algorithms for prediction and optimization of $\mathrm{NO}_{\mathrm{x}}$ formation for a $600 \mathrm{MW}$ capacity pulverized coal burned utility boiler. They found a close correlation between the $\mathrm{NO}_{\mathrm{x}}$ emissions and the operating parameters of the boiler and the coal quality. $\mathrm{NO}_{\mathrm{x}}$ emissions from a circulating fluidized bed boiler have also been modeled using ANNs [6]. Zhou et al. [7] have reported that the ANN technique was more convenient and direct, and could achieve a good prediction performance compared with the other modeling techniques such as computational fluid dynamics for the prediction of $\mathrm{NO}_{\mathrm{x}}$ emission. Teruel et al. [8] have investigated ash deposits in coal-fired boilers, and developed an ANN model for the fouling and the cleaning in the furnace. Other than environmental emissions, there are also applications of ANN modeling in the literature, for estimation of combustion rate of coal [9], optimization of the operating conditions of pulverized coal combustion [10], monitoring of combined heat and power plants [11,12], prediction of hardgrove grindability index [13], gross calorific value [14], and coal rank parameters [15].

Coal is the most widely used fuel for electricity generation in the world, and it is expected to maintain its importance through 2035. In 2007 , coal-fired electricity generation accounted for $42 \%$ of the world electricity supply; and in 2035, its share is predicted to remain approximately the same [16]. In Turkey, by the year of 2010 , 
the production of electricity was maintained mainly from natural gas (45.9\%), coal (25.3\%), and hydraulic resources (24.5\%); coal being the second most important resource of electricity [17].

Coal-fired power plants utilized in electricity generation encounter several environmental problems, one of them being the formation of ash. As a result of the combustion process, ash is formed in two forms: the fly ash and the bottom ash. Fly ash is the fine particles of ash in the flue gas, and bottom ash is the larger and heavier particles depositing at the bottom of the furnaces as a thick layer. Vast amounts of coal ash are produced worldwide as a result of coal combustion and most of the ash is discarded mainly to landfills, ponds, or sea. The application of the bottom ash to soil and water may give rise to unacceptable levels of pollution [18]. Other issues encountered related to the formation of bottom ash are the deterioration of heat transfer and increased corrosion in furnaces and pipes. The amount of bottom ash produced from the combustion of coal is mainly influenced by the properties of coal, coal milling, and combustion conditions.

Durgun and Genc [19] applied regression models to study effects of coal properties on the production rate of combustion solid residue in a pulverized coal-fired power plant. They investigated the dependency of the production rate of bottom ash on the fixed carbon, moisture and ash contents of coals, but they could not observe any correlations between the coal type and the amount of bottom ash produced. They also evaluated the ratio of amount of bottom ash produced to amount of coal burned (Bottom ash/Coal burned) depending on the lower heating value (LHV) of coals fired, and observed a linear relation between the (Bottom ash/Coal burned) ratio and the LHV of coals with a coefficient of determination of 0.76 . They concluded that the most important parameter in determining the production rate of bottom ash from the power plant they investigated was the calorific value of the coals fired. Since ANN approach is known to be successfully applicable to combustion systems, in this study, we aimed to investigate the ANN prediction of (Bottom ash/Coal burned) ratio with higher coefficient of determination and lower error than those obtained with regression analysis using the same data (i.e., coal properties and power plant operating data).

\section{Coal properties}

Tertiary subbituminous and lignite coals are the most abundant and widespread coal deposits in Turkey $[20,21]$. These coal deposits have low calorific values and high ash contents. The total lignite and subbituminous coal reserve of Turkey is 8.3 billion tons [22]. Coal produced in Turkey is mainly consumed in power plants and partly in industrial and domestic uses.

Catalagzi pulverized coal-fired power plant (CATES) is located at about $17 \mathrm{~km}$ east of Zonguldak city center, Western Black Sea cost of Turkey. It has two units with a total electricity generating capacity of $300 \mathrm{MW}(2 \times 150 \mathrm{MW})$. CATES consumes about 5000-5500 tons of coal per day. This power plant utilizes the mixture of low-rank bituminous coal with coal sludge generated from a washing process, as the main fuel. The operating data of the CATES for the year 2007 and the properties of coals utilized were used in this study as the ANN modeling data. The specified properties of the coal sludge and low-rank bituminous coal by the power plant are shown in Table 1. In this study, three properties of the coals fired; moisture content, ash content, and LHV, were selected as the inputs of the ANN model. The properties of the coals were determined based on proximate analysis data (moisture and ash contents) and calorific value analysis data of the coals. The proximate and calorific value analyses of coals were performed according to ASTM D5142 [23] and ASTM D5865 [24] standards, respectively. The details of the performed analyses and the equipments used were given
Table 1

Specified properties of the coal sludge and low-rank bituminous coal by the power plant.

\begin{tabular}{|c|c|c|}
\hline \multirow{2}{*}{$\frac{\text { Parameter }}{\text { Coal type }}$} & \multicolumn{2}{|l|}{ Design values } \\
\hline & Coal sludge & Coal \\
\hline Particle diameter & $0-10 \mathrm{~mm}$ & $0-10 \mathrm{~mm}$ \\
\hline Moisture & $16 \pm 4 \%$ & $7 \pm 4 \%$ \\
\hline Ash & $47 \pm 3 \%$ & $35 \pm 3 \%$ \\
\hline Sulfur & $0.3-0.4 \%$ & $0.3-0.4 \%$ \\
\hline LHV & $3000 \pm 100 \mathrm{kcal} / \mathrm{kg}$ & $4400 \pm 200 \mathrm{kcal} / \mathrm{kg}$ \\
\hline
\end{tabular}

elsewhere $[19,25]$. The major and trace element concentrations in feed coals of the CATES power plant were reported in [26]. The ratio of the amount of bottom ash formed to the amount of coal burned (Bottom ash/Coal burned) was predicted as the model output. The minimum, maximum and average values of the input and output parameters are given in Table 2 .

\section{ANN model}

ANNs contain simple processing elements called neurons organized into layers [27-29]. They are interconnected parallel systems. ANNs resemble human brain in two respects; knowledge is acquired by the network through a learning process, and the interconnection strengths known as synaptic weights are used to store the knowledge.

In this study, a feed-forward, multi-layer perceptron (MLP) type of ANN model was used to predict the (Bottom ash/Coal burned) ratio in a pulverized coal-fired power plant (Fig. 1). The network architecture consists of one input layer, one hidden layer, and one output layer. The three neurons in the input layer are associated with the three input parameters. The information is transferred from the input layer to the hidden layer neurons. Each neuron in the hidden layer is connected to every neuron in the input and output layers by the connection weights. These adaptable connection weights are used to store the knowledge within the network. The sum of the weighted inputs is passed through an activation function in each hidden neuron, and the outputs of the hidden neurons are calculated;

$y_{j}=f\left(\right.$ net $\left._{j}\right)=f\left(\sum_{j} w_{i j} x_{i}+b_{j}\right)$

where $y_{j}$ is the output of the $j$ th neuron, $f$ the activation function, net $_{j}$ the net input to the $j$ th neuron, $w_{i j}$ the connection weight from the $i$ th neuron in the previous layer to the $j$ th neuron in the current layer, $x_{i}$ the input from the $i$ th neuron to the $j$ th neuron, and $b_{j}$ is the bias [30]. The activation function used was sigmoid function;

$f\left(\right.$ net $\left._{j}\right)=\frac{1}{1+e^{- \text {net }_{j}}}$

Sigmoid function is continuous and differentiable, which will be very important in weight adaptation during the training process. It

Table 2

Minimum, maximum, and average values of model inputs and an output parameter.

\begin{tabular}{lrrr}
\hline Parameter & Minimum & Maximum & Average \\
\hline Input parameters & & & \\
Moisture (\%, wet basis) & 9.70 & 16.10 & 12.78 \\
$\begin{array}{l}\text { Ash (\%, dry basis) } \\
\text { LHV (kcal/kg) }\end{array}$ & 30.60 & 45.70 & 40.13 \\
$\begin{array}{l}\text { Output parameter } \\
\text { (Bottom ash/Coal burned) }(\mathrm{kg} / \mathrm{kg})\end{array}$ & 0.0612 & 0.0914 & 0.0806 \\
\hline
\end{tabular}




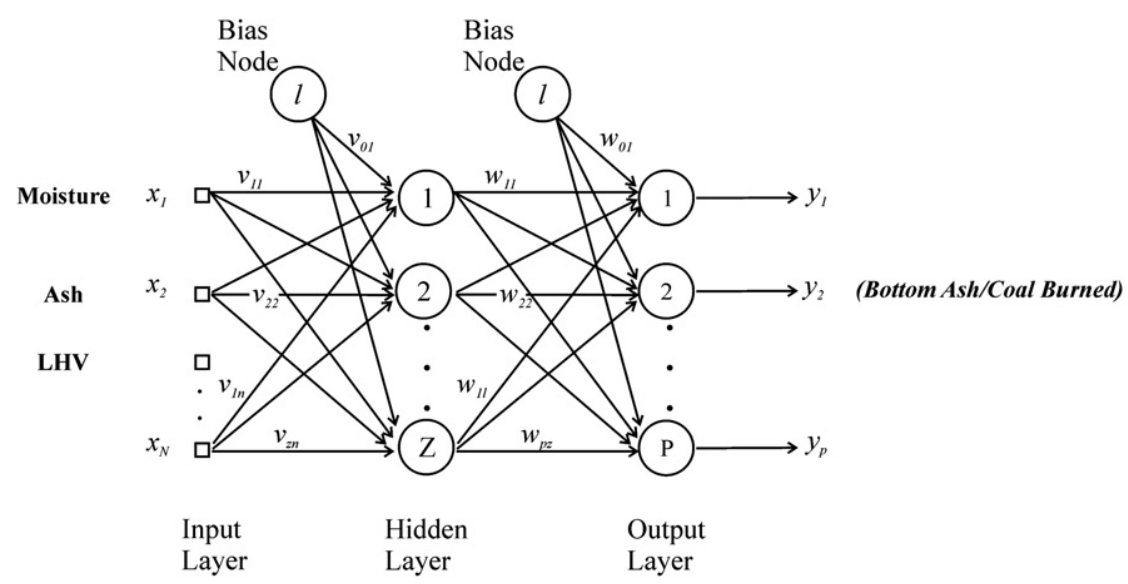

Fig. 1. Three-layer, feed-forward type neural network architecture for the prediction of (Bottom ash/Coal burned) ratio.

produces a nonlinear response in the interval of $[0,1]$, and it is frequently preferred in nonlinear mapping. The output parameter is associated with one output neuron. The output neuron performs the same operation as the hidden layer neurons.

Data were normalized before the training to match the range of the hidden layer's activation function (i.e., $0-1$ for the sigmoid activation function) using,

$x_{\text {normalized }}=\frac{\left(x_{\text {original }}-x_{\text {minimum }}\right)}{\left(x_{\text {maximum }}-x_{\text {minimum }}\right)}$

The network output was rescaled to the original range to interpret the results obtained from the model.

The learning of the ANN model is accomplished by the training process. The training data set is used for the training procedure. In this study, back-propagation algorithm was applied to train networks. Information is processed in the forward direction to determine the output value of the each neuron in the output layer, and then the following error between the desired output and the model prediction is computed;

$E=\sum_{k} \sum_{n}\left(d_{n k}-y_{n k}\right)^{2}$

where $E$ is the error, $k$ is an index over the system output, $n$ is an index over the input patterns, $d$ is a component of the desired or target output vector $\boldsymbol{D}$, and $y$ is a component of the network output vector $\boldsymbol{Y}$. This error is then propagated in the backward direction to update the connection weights using gradient decent method along with the chain rule of derivatives;

$w_{i j}^{\text {new }}=w_{i j}^{\text {old }}-\delta \frac{\partial E}{\partial w_{i j}}$

where $\delta$ is the learning rate which controls the rate of change in the connection weights. The training of the model is carried on until an acceptable error tolerance value is reached. The error tolerance determines how accurate the neural network prediction must be to be regarded as correct. After the training, the performance of the model was tested using the testing data set.

\section{Results and discussion}

\subsection{Analysis of the accuracy of ANN model}

The total 653 data obtained from CATES plant were randomized and divided into two sub-sets (Data Group I) as the training set (90\% of the data) and the testing set ( $10 \%$ of the data). The performance criteria were selected as coefficient of determination $\left(R^{2}\right.$, Square of the Pearson product moment correlation coefficient $R$ ), root mean square error (RMSE), and mean absolute error (MAE);

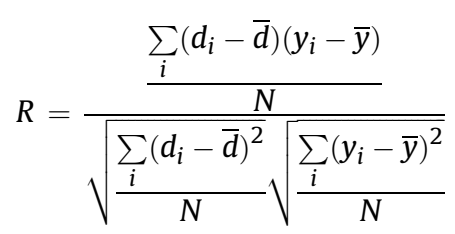

$\mathrm{RMSE}=\sqrt{\frac{1}{N} \sum_{i}\left(d_{i}-y_{i}\right)^{2}}$

$\mathrm{MAE}=\frac{1}{N} \sum_{i}\left|d_{i}-y_{i}\right|$

The effects of model parameters (i.e., learning rate, number of neurons in the hidden layer, and tolerance value) were investigated, and the performance of the model was optimized.

In order to decide the optimum neuron number in the hidden layer and the learning rate, different networks were tested by varying the neuron number from 5 to 35 at two different learning rates $(\delta=0.2$ and 0.5 ). The tolerance value was kept constant at 0.1 . RMSE was calculated for each network. Minimum RMSE was obtained for learning rate of 0.2 and 29 neurons in the hidden layer (Fig. 2). The performance of the network did not change significantly for the higher number of neurons in the hidden layer.

The effects of tolerance value on the model performance were investigated using 29 hidden neurons and learning rate of 0.2 . Two different tolerance values $(0.05$ and 0.1$)$ were tested. Calculated performance criteria for these values are given in Table 3. Considering RMSE, MAE and $R^{2}$ for both training and testing sets, the best results were obtained for the tolerance of 0.05 . However, the training time was considerably longer for this tolerance. Scatter plots of predicted (Bottom ash/Coal burned) ratios against actual values are shown in Figs. 3 and 4 for the training and testing data sets, respectively. The predicted and actual (Bottom ash/Coal burned) ratios were in good agreement. The deviations from the diagonal were random and not systematic. The coefficient of determination was obtained as 0.988 for the training set and as 0.984 for the testing set. The generalization capability of the network was also acceptable since there were not significant differences between the values of performance criteria for the training and testing sets for a given tolerance (Table 3). 


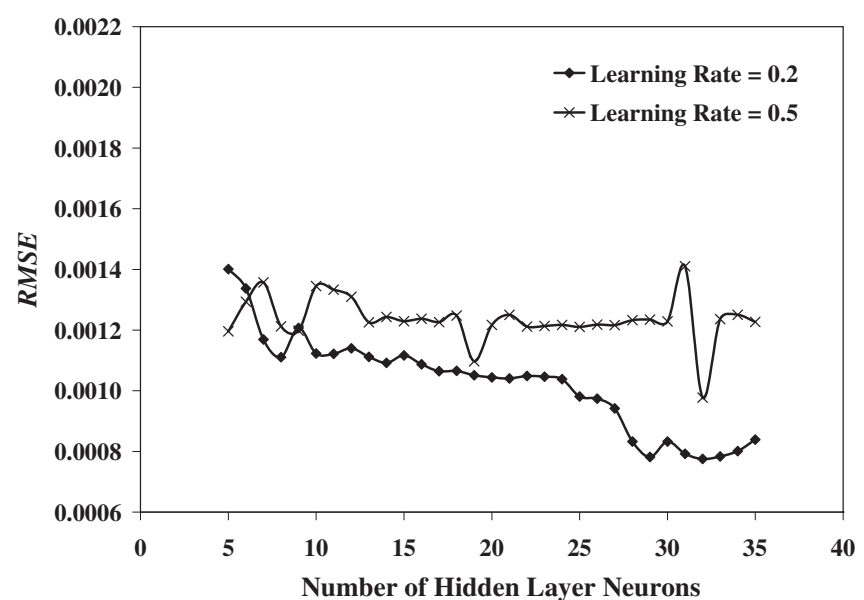

Fig. 2. Change of RMSE with hidden neuron number for different learning rates.

To determine the effects of data sub-sets used in training and testing on the prediction performance of the network, data were rearranged and new training and testing sets (Data Group II) formed. The model performance was evaluated again. The percentages of the total data used in training (90\%) and testing (10\%) for Data Group II were the same as before. The lowest RMSE value was obtained for 6 neurons in the hidden layer when previously optimized model parameters (learning rate of 0.2 and tolerance value of 0.05 ) were used. RMSE, MAE and $R^{2}$ values are given in Table 4 for Data Group II. $R^{2}$ value was calculated as 0.981 for the training set and as 0.976 for the testing set. The cross plots of predicted and actual (Bottom ash/ Coal burned) ratios for the training (Fig. 5) and testing (Fig. 6) sets fall close to diagonal line, which indicate a good prediction performance of the network. The comparable results were obtained for the performance indicators RMSE, MAE and $R^{2}$ with Data Group I and Data Group II (Tables 3 and 4).

The coefficients of determination obtained in this study with ANN modeling approach for testing sets of Data Group I $\left(R^{2}=0.984\right)$ and Data Group II $\left(R^{2}=0.976\right)$ were higher than the value reported in the literature $\left(R^{2}=0.76\right)$ for the regression analysis using the same data [19]. With a limited number of experimental results (Total of 12 cases were divided into two groups for training (11 cases) and testing (one case)), Zhou et al. [7] have modeled the level of unburned carbon in fly ash (i.e., carbon burnout characteristics) of a $600 \mathrm{MW}$ pulverized coal-fired boiler using ANN technique. The relative error between the experimental measurement and the model prediction was $4.8 \%$. We calculated the average relative errors for testing sets of Data Group I and Data Group II as $0.629 \%$ (maximum relative error $=2.592 \%$ ) and $0.803 \%$ ( maximum relative error $=1.932 \%$ ), respectively.

\subsection{Sensitivity analysis}

The influence of input parameters on the (Bottom ash/Coal burned) ratio was investigated by sensitivity analysis. In this analysis, first the network was trained and the connection weights were fixed. Then, one at a time each input parameter was varied around its mean value while the other inputs were kept constant at their

Table 3

Performance of the ANN model for two different tolerance values (learning rate $=0.2$; number of hidden neurons $=29$ ).

\begin{tabular}{lllllllll}
\hline \multirow{2}{*}{ Tolerance } & \multicolumn{2}{l}{ Training set } & & \multicolumn{2}{l}{ Testing set } \\
\cline { 2 - 3 } & MAE & RMSE & $R^{2}$ & & MAE & RMSE & $R^{2}$ \\
\hline 0.05 & 0.000424 & 0.000520 & 0.988 & & 0.000511 & 0.000618 & 0.984 \\
0.1 & 0.000702 & 0.000923 & 0.946 & & 0.000606 & 0.000782 & 0.948 \\
\hline
\end{tabular}

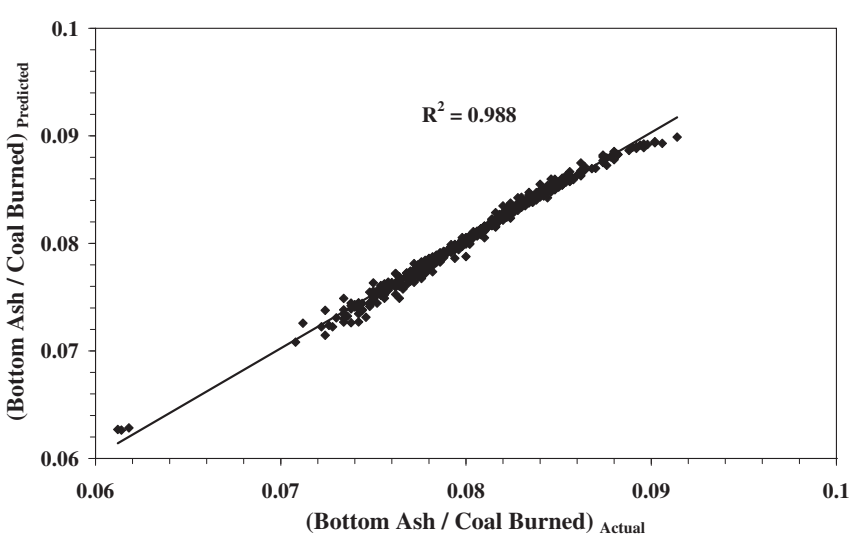

Fig. 3. Cross plot of predicted and actual (Bottom ash/Coal burned) ratios for the training set of data group I.

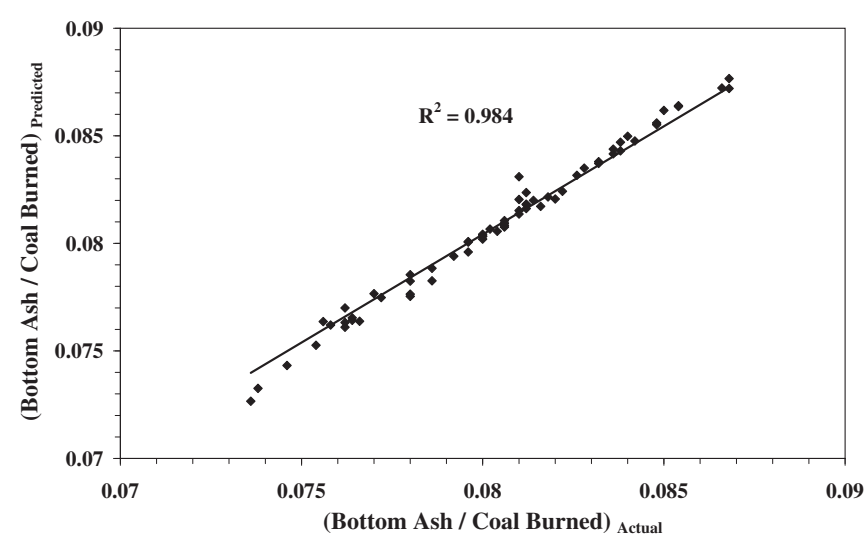

Fig. 4. Cross plot of predicted and actual (Bottom ash/Coal burned) ratios for the testing set of data group I.

mean values, and the change in the output parameter was calculated. The sensitivity factor for the input $a$ is given by,

$S_{a}=\frac{\sum_{p=1}^{P} \sum_{i=1}^{o}\left(y_{i p}-\overline{y_{i p}}\right)^{2}}{\sigma_{a}^{2}}$

where $\overline{y_{i p}}$ is the $i$ th output obtained with the fixed weights for the $p$ th pattern, $o$ is the number of network outputs, $P$ is the number of patterns, and $\sigma_{a}^{2}$ is the variance of the input perturbation [30].

The sensitivity factors for input parameters are given in Fig. 7. These factors were calculated for the best network architecture obtained for Data Group I (i.e., 29 neurons in the hidden layer, learning rate of 0.2 , and tolerance value of 0.05 ). As can be seen in this figure, ash content has the highest sensitivity factor thus is the most effective parameter on the prediction of the model output (Bottom ash/Coal burned) ratio. The effects of the other input parameters are considerably lower compared to ash content, and the moisture content being the least effective on the formation of bottom ash. Previously, the correlation between the ash content of the coal and the bottom ash produced could not be obtained by regression analysis in the study of Durgun and Genc [19]. In contrast, a higher $R^{2}$ value between the (Bottom ash/Coal burned)

Table 4

Performance of the ANN model for data group II (learning rate $=0.2$; number of hidden neurons $=6$; Tolerance $=0.05$ )

\begin{tabular}{llll}
\hline Data set & MAE & RMSE & $R^{2}$ \\
\hline Training & 0.000613 & 0.000709 & 0.981 \\
Testing & 0.004375 & 0.005328 & 0.976 \\
\hline
\end{tabular}




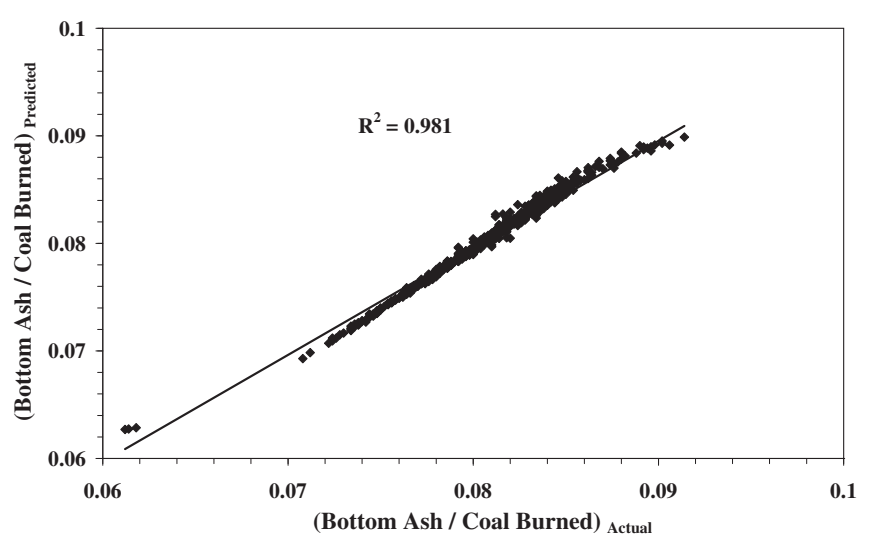

Fig. 5. Cross plot of predicted and actual (Bottom ash/Coal burned) ratios for the training set of data group II.

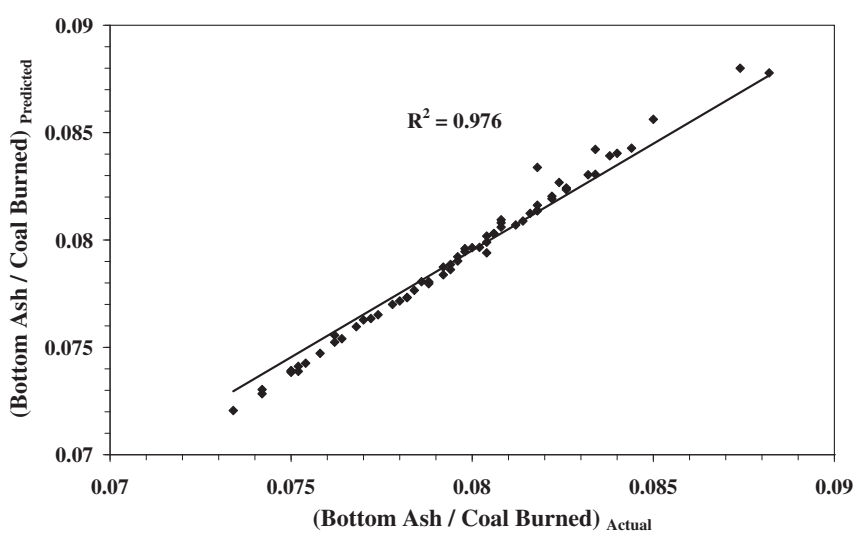

Fig. 6. Cross plot of predicted and actual (Bottom ash/Coal burned) ratios for the testing set of data group II.

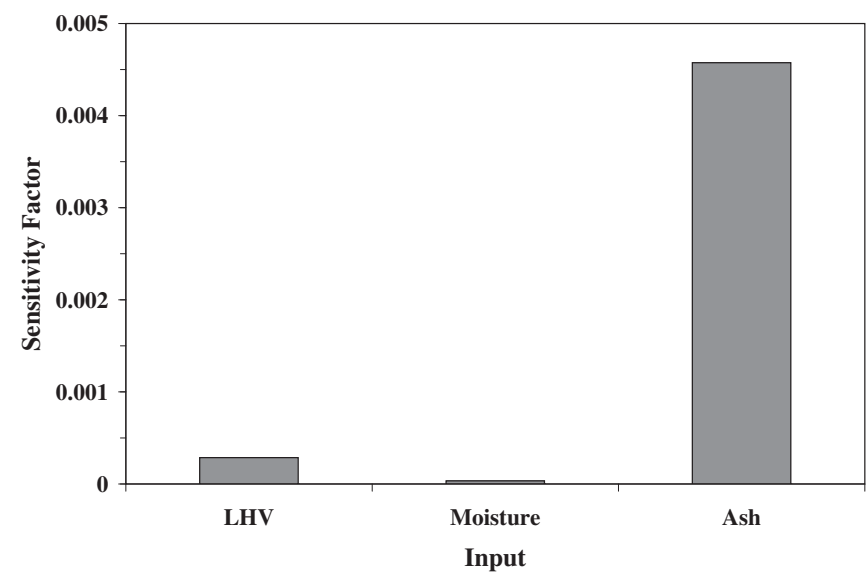

Fig. 7. Sensitivity coefficients of the input parameters for the prediction of (Bottom ash/ Coal burned) ratio.

ratio and LHV $\left(R^{2}=0.76\right)$ was reported. However, in this study, it was shown that the formation of bottom ash was mainly dependent on the ash content of the source coals, among the parameters investigated using ANN modeling approach.

\section{Conclusions}

A multi-layer, feed-forward ANN model was used for the prediction of (Bottom ash/Coal burned) ratio from the coal properties (i.e., moisture content, ash content, and LHV) and plant operating data with a high coefficient of determination and small error.

Two different data sets were tested, and it was found that the performance of the ANN model developed was independent from the data set used in training and testing. The $R^{2}$ values obtained ( $>0.97$ ) were higher compared to the values reported in the literature using regression analysis (0.76).

The effect of each input parameter was determined by sensitivity analysis. Ash content of the coals was found to be the most important parameter on the formation of bottom ash.

ANN modeling technique was successfully applied for the prediction of (Bottom ash/Coal burned) ratio in a pulverized coalfired power plant.

\section{References}

[1] Kalogirou SA. Artificial intelligence for the modeling and control of combustion processes: a review. Progress in Energy and Combustion Science 2003;29:515-66

[2] Inal F, Tayfur G, Melton TR, Senkan SM. Experimental and artificial neura network modeling study on soot formation in premixed hydrocarbon flames. Fuel 2003;82:1477-90.

[3] Inal F. Artificial neural network predictions of polycyclic aromatic hydrocarbon formation in premixed n-heptane flames. Fuel Processing Technology 2006;87:1031-6.

[4] Chong AZS, Wilcox SJ, Ward J. Prediction of gaseous emissions from a chain grate stoker boiler using artificial neural networks of ARX structure. IEE Proceedings-Science, Measurement and Technology 2001;148:95-102.

[5] Hao Z, Kefa C, Jianbo M. Combining neural network and genetic algorithms to optimize low NOx pulverized coal combustion. Fuel 2001;80:2163-9.

[6] Liukkonen M, Heikkinen M, Hiltunen T, Halikka E, Kuivalainen R, Hiltunen Y. Artificial neural networks for analysis of process states in fluidized bed combustion. Energy 2011;36:339-47.

[7] Zhou H, Cen K, Fan J. Modeling and optimization of the NOx emission characteristics of a tangentially fired boiler with artificial neural networks. Energy 2004;29:167-83.

[8] Teruel E, Cortes C, Diez LI, Arauzo I. Monitoring and prediction of fouling in coal-fired utility boilers using neural networks. Chemical Engineering Science 2005;60:5035-48.

[9] Zhu Q Jones JM, Williams A, Thomas KM. The predictions of coal/char combustion rate using an artificial neural network approach. Fuel 1999;78:1755-62.

[10] Hao Z, Qian X, Cen K, Fan J. Optimizing pulverized coal combustion performance based on ANN and GA. Fuel Processing Technology 2003;85:113-24.

[11] De S, Kaiadi M, Fast M, Assadi M. Development of an artificial neural network model for the steam process of a coal biomass cofired combined heat and power (CHP) plant in Sweden. Energy 2007;32:2099-109.

[12] Fast M, Palme T. Application of artificial neural networks to the condition monitoring and diagnosis of a combined heat and power plant. Energy 2010; 35:1114-20.

[13] Ozbayoglu G, Ozbayoglu AM, Ozbayoglu ME. Estimation of Hardgrove grindability index of Turkish coals by neural networks. International Journal of Mineral Processing 2008;85:93-100.

[14] Mesroghli S, Jorjani E, Chelgani SC. Estimation of gross calorific value based on coal analysis using regression and artificial neural networks. International Journal of Coal Geology 2009;79:49-54.

[15] Chelgani SC, Mesroghli S, Hower JC. Simultaneous prediction of coal rank parameters based on ultimate analysis using regression and artificial neural network. International Journal of Coal Geology 2010;83:31-4.

[16] U.S. Energy Information Administration. International energy outlook 2010 DOE/EIA-0484; 2010.

[17] Republic of Turkey Ministry of Energy and Natural Resources. Electricity production sector report; 2010 [In Turkish].

[18] Reijnders L. Disposal, uses and treatments of combustion ashes: a review. Resources, Conservation and Recycling 2005;43:313-36.

[19] Durgun D, Genc A. Effects of coal properties on the production rate of combustion solid residue. Energy 2009;34:1976-9.

[20] Palmer CA, Tuncali E, Dennen KO, Coburn TC, Finkelman RB. Characterization of Turkish coals: a nationwide perspective. International Journal of Coal Geology 2004;60:85-115.

[21] Toprak S. Petrographic properties of major coal seams in Turkey and their formation. International Journal of Coal Geology 2009;78:263-75.

[22] Tuncali E, Ciftci B, Yavuz N, Toprak S, Koker A, Aycik H, et al. Chemical and technological properties of Turkish tertiary coals. Ankara-Turkey: Genera Directorate of Mineral Research and Exploration; 2003.

[23] ASTM D5142. Proximate analysis of the analysis sample of coal and coke by instrumental procedures.

[24] ASTM D5865. Gross calorific value of coal and coke.

[25] Durgun D. Determination of production rate of solid waste in Catalagzi thermal power plant depending on coal quality, M.Sc. thesis: Zonguldak 
Karaelmas University, Graduate School of Natural and Applied Sciences, Department of Environmental Engineering; 2008 [In Turkish].

[26] Karayigit AI, Gayer RA, Querol X, Onacak T. Contents of major and trace elements in feed coals from Turkish coal-fired power plants. International Journal of Coal Geology 2000;44:169-84.

[27] Nelson MM, Illingworth WT. A practical guide to neural nets. Massachusetts: Addison-Wesley; 1994.
[28] Fausett L. Fundamentals of neural network architectures, algorithms, and applications. New Jersey: Prentica-Hall; 1994.

[29] Haykin S. Neural networks: a guided tour. In: Sinha NK, Gupta MM, Zadeh LA editors. Soft computing and intelligent systems: theory and applications. Academic Press; 2000. p. 71-80.

[30] Principe JC, Euliano NR, Lefebvre WC. Neural and adaptive systems: fundamentals through simulations. New York: John Wiley \& Sons; 1999. 